Original Research Paper

\title{
Bioconversion of Corn Steep Liquor to Biofertilizer by Symbiotic Fermentation
}

\author{
${ }^{1}$ Xiaojie Ren, ${ }^{1}$ Zhuangzhuang He, ${ }^{1}$ Huihui Peng, ${ }^{1}$ Jing Zhang, ${ }^{1}$ Sihua Wang, \\ ${ }^{2}$ Yubin Zhao, ${ }^{1}$ Xiaoyu Li, ${ }^{1}$ Yuanda Song, ${ }^{1,3,4}$ Xinhe Zhao and ${ }^{1}$ Chengye Ma \\ ${ }^{1}$ School of Agriculture Engineering and Food Science, Shandong University of Technology, Zibo, China \\ ${ }^{2}$ Luzhou Bio-Chem Technology Limited, Linyi, China \\ ${ }^{3}$ State Key Laboratory of Microbial Technology, Shandong University, Qingdao, China \\ ${ }^{4}$ Chongqing Academy of Science and Technology, Chongqing, China
}

Article history

Received: 27-07-2021

Revised: 01-11-2021

Accepted: 12-11-2021

Corresponding Author:

Xinhe Zhao

School of Agriculture

Engineering and Food Science,

Shandong University of

Technology, Zibo, China

Emai: zhaoxinhe2018@163.com

Chengye Ma

School of Agriculture

Engineering and Food Science,

Shandong University of

Technology, Zibo, China

Email: mcycn2002@163.com

\begin{abstract}
Corn Steep Liquor (CSL) is wastewater from corn starch industry. The huge amount generation made it as a serious environmental problem. But CSL is nutrient-rich with diverse amino acids and other trace elements. In this study, symbiotic biofertilizer was studied using CSL as main substrate. In this study, 9 industrial strains, which were recognized as high performance species in the biofertilizer industry were collected, including four bacillus, four fungus and one yeast species. Three dominant strains were selected finally, depending on the ability to dissolve phosphorus, ability for protein hydrolysis and cell growth. They were Bacillus subtilis 3301, Bacillus licheniformis and Aspergillus Niger. The results expressed that the highest growth cell count of Bacillus subtilis 3301 reached $3.1 \times 10^{9} \mathrm{CFU} / \mathrm{mL}$, the highest protein hydrolysis capacity of Bacillus licheniformis reached $600 \mathrm{mg} / \mathrm{L}$ and the highest phosphorus-dissolving capacity of Aspergillus Niger reached $1100 \mathrm{mg} / \mathrm{L}$ respectively. Then, symbiotic fermentation of the three strains was carried out both in shake-flask culture and fermentation tank (5 L). Interestingly, series of significant data of symbiotic fermentation were obtained, which were different from individual cultures. Especially, the total growth cell count in the $5 \mathrm{~L}$ scale fermenter culture was higher than individual cultures, which proved the mutual promotion effect between different strains. This research would provide a new view to utilize the waste of corn steep liquor as high value-added agricultural products.
\end{abstract}

Keywords: Corn Steep Liquor, Biofertilizer, Symbiotic Fermentation, Microbiome

\section{Introduction}

Corn starch is the main resource for producing glucose and various sugar derivatives. During the industrial process of corn starch production, corn wet milling method is mainly applied with a high energy intensive process and environmentally unfriendly soaking water (Liggett and Koffler, 1948; Zhang and Jia, 2018). Corn Steep Liquor (CSL) is a concentrated liquid derived from the water that is used in the initial stage of the corn wet milling process. As a huge amount of by-product, the yield of CSL is about one billion tons per year globally. However, due to its foul smell, high acid and aflatoxins content, which greatly restricted its application. Currently, the CSL was mainly utilized for feeding in fodder, but the consumed amount was limited. This phenomenon led to CSL overstocking and discharged as a sewage by factories, resulted in seriously environment problem. In fact, CSL is rich in nutrients such as proteins, amino acids, carbohydrates, vitamins and minerals and it's considered an excellent source of organic nitrogen for microorganisms (Salam and Ishaq, 2019). As previously reported, the CSL is also applicable to use as a component of growth media, fertilizers and soil conditioners when directly added into soil (Filipović et al., 2001; Obayori et al., 2015). Low concentration of corn steep liquor promotes seed germination, plant growth in soybean and promotes lettuce growth via its antifungal and bio-stimulatory effects (Chinta et al., 2014; Zhu et al., 2019).

However, to the best of our knowledge, there have been few reports on the use of CSL for the production of biofertilizer by symbiotic fermentation. This study 
investigated the feasibility of using CSL as the main raw material for production of bio-fertilizer as Plant Growth-Promoting Microbes (PGPM). The study developed an innovative view for applying CSL nutrition to cultivate various microorganism for improving the soil matrix and promoting the growth of plants. While reducing CSL overstock, the developed bacteria as biofertilizers can reduce the use of chemical fertilizers and subsequently to reduce the environmental pollution.

However, to the best of our knowledge, there have been few reports on the use of CSL for the production of biofertilizer by symbiotic fermentation. This study investigated the feasibility of using CSL as the main raw material for production of bio-fertilizer as Plant GrowthPromoting Microbes (PGPM). The study developed an innovative view for applying CSL nutrition to cultivate various microorganism for improving the soil matrix and promoting the growth of plants. While reducing CSL overstock, the developed bacteria as biofertilizers can reduce the use of chemical fertilizers and subsequently to reduce the environmental pollution.

\section{Materials and Methods}

\section{Raw Materials}

CSL were obtained by Luzhou Bio-chem Technology Limited. The CSL with pH 4.3 \pm 0.1 , Amino Acid Nitrogen (AAN) content of $9.71 \pm 0.18 \mathrm{~g} / \mathrm{L}$, moisture content of $67.14 \pm 3.3 \%$, total sugar content of $4.52 \pm 0.1 \%$, reducing sugar content of $40.33 \pm 0.92 \mathrm{~g} / \mathrm{L}$, ash content of $7.46 \pm 0.3 \%$, soluble phosphorus content of $4.39 \pm 1.18 \mathrm{~g} / \mathrm{L}$, which were measured in previous studies (Zhao et al., 2020).

Nine strains were collected from industrial production, which including four bacteria (Bacillus subtilis 3301, B. subtilis A308, B. subtilis N52, B. Licheniformis F18), one yeast (Saccharomyces cerevisiae), four fungi (Aspergillus Niger, A. oryzae, Trichoderma harzianum, T. longi). These strains were defined as PGPMs for developing a composite bio-fertilizer.

\section{Methods}

\section{Culture}

The corn pulp liquor stock was diluted 5 times with water $20 \%(w / v)$ and was adjusted to $\mathrm{pH}$ 6.5-7.0 with $\mathrm{NaOH}(1 \mathrm{M})$. Then the CSL medium was sterilized at $121^{\circ} \mathrm{C}$, for $20 \mathrm{~min}$. The bacteria were cultivated in nutrient broth LB $(10 \mathrm{~g} / \mathrm{L}$ tryptome, $5 \mathrm{~g} / \mathrm{L}$ yeast extract, $5 \mathrm{~g} / \mathrm{L} \mathrm{NaCl}$ ); while fungi were cultivated in a modified Martin medium with peptone $5.0 \mathrm{~g} / \mathrm{L}$, dipotassium hydrogen phosphate $1.0 \mathrm{~g} / \mathrm{L}$, magnesium sulfate $0.5 \mathrm{~g} / \mathrm{L}$, yeast extract powder $2.0 \mathrm{~g} / \mathrm{L}$, glucose $20.0 \mathrm{~g} / \mathrm{L}$ for seed culture. All fermentation processes were performed by transferring $10 \%(\mathrm{w} / \mathrm{v})$ of selected strain inoculums. A $50 \mathrm{~mL}$ CSL medium was added in $250 \mathrm{~mL}$ flask and incubated at $30^{\circ} \mathrm{C}$ with shaking speed $160 \mathrm{rpm}$ for $72 \mathrm{~h}$ for biomass production.

\section{CSL Microbial Diversity Investigation}

For deep understanding microbial preference in CSL, the original microbial diversity was analyzed by high-throughput sequencing technology. Genomic DNA was extracted using the Mag-Bind Soil DNA Isolation Kit (Omega Bio-tek, Norcross, GA, U.S.) according to the manufacturer's instructions. The extraction procedures of CSL were conducted in triplicate. Each sample was tested for DNA integrity by agarose gel electrophoresis. Qubit2.0 DNA detection kit was used to accurately quantify genomic DNA. The primers $27 \mathrm{~F}$ and $1541 \mathrm{R}$ were used for the amplification of bacterial $16 \mathrm{~S}$ rDNA genes. High-throughput sequencing was performed using an Illumina Miseq ${ }^{\mathrm{TM}}$ platform. The Ribosomal Database Project (RDP) classifier was applied for the alignment analysis of each sample sequence and the species information of the original flora in CSL was expressed at the genus level.

\section{Phosphorus-Dissolving Characteristics Determination}

The ability of the tested strains to dissolve different insoluble Phosphates (P) in liquid medium were investigated in Pikovskaya (PVK) medium containing $5.0 \mathrm{~g} \mathrm{Ca}_{3}\left(\mathrm{PO}_{4}\right)_{2}$ (Ogbo, 2010). To determine the dissolving ability of organophosphorus, $\mathrm{Ca}_{3}\left(\mathrm{PO}_{4}\right)_{2}$ was substituted by phosphatidylcholine in the PVK medium. Inoculate $10 \%(\mathrm{v} / \mathrm{v})$ of the tested strains individually into $50 \mathrm{~mL}$ inorganic/organic PVK mediums and cultured them at $30^{\circ} \mathrm{C}, 160 \mathrm{rpm}$, for $12 \mathrm{~h}$. All the experiments were carried out in triplicates. The soluble phosphorus content and $\mathrm{pH}$ of each culture were determined after 72 h. $\triangle P=C_{P}-C_{P 0}\left(C_{P}\right.$ the content of soluble phosphorus in fermentation broth. $\mathrm{C}_{\mathrm{P} 0}$ represented the initial content in CSL medium without microbial inoculation).

\section{Protein-Dissolving Characteristics Determination}

In order to study the decomposition ability of protein to Amino Acid Nitrogen (AAN) by different strains, $\triangle \mathrm{AAN}$ was determined for different strains cultured at $72 \mathrm{~h}$ in CSL medium. $\triangle \mathrm{AAN}=\mathrm{C}_{\mathrm{N}}-\mathrm{C}_{\mathrm{N} 0}\left(\mathrm{C}_{\mathrm{N}}\right.$ the content of Amino Acid Nitrogen (AAN) in fermentation broth; $\mathrm{C}_{\mathrm{N} 0}$ represented the initial AAN content in CSL medium without microbial inoculation).

The Effect of Different Neutralizer on PGPMs' Biomass, Phosphorus and Protein Dissolving Ability in CSL Culture

The initial $\mathrm{pH}$ of corn pulp is very low ( 2) and a large amount of $\mathrm{pH}$ regulator need to be added to adjust the CSL medium to neutral. However, because different $\mathrm{pH}$ 
regulator contains different kinds of salt ions and the addition of these salt ions may have different effects on the growth of PGMs as well as on the ability of phosphorus and nitrogen hydrolysis. Therefore, we did a comparative study, to find out the best $\mathrm{pH}$ regulator for promoting microbial proliferation in corn pulp.

In this test, the CSL medium $20 \%$ (w/v) was adjust to $\mathrm{pH} 6.5$ with different $\mathrm{pH}$ neutralizers, which including $\mathrm{NaOH}(2 \mathrm{M}), \mathrm{KOH}(2 \mathrm{M}), \mathrm{Ca}(\mathrm{OH})_{2}(2 \mathrm{M})$ and $\mathrm{NH}_{3} \cdot \mathrm{H}_{2} \mathrm{O}$ (2M), respectively. Then three selected dominant strains (Bacillus subtilis 3301, Bacillus licheniformis and Aspergillus Niger) were cultured in CSL mediums and the fermentation processes were sampled to determine the indicators.

\section{Symbiotic Fermentation}

Spore suspension of A. Niger was inoculated into a $5 \mathrm{~L}$ fermenter with $5 \%$ inoculum volume. The initial aeration rate was $2 \mathrm{NL} / \mathrm{min}$; the agitation speed was $300 \mathrm{rpm}$ and the $\mathrm{pH}$ was controlled to 6.5 by automatic flow of $2 \mathrm{~mol} / \mathrm{L} \mathrm{KOH}$ and $\mathrm{H}_{2} \mathrm{SO}_{4}$, respectively; the initial culture temperature was $30^{\circ} \mathrm{C}$. The seed solution of B. subtilis and B. licheniformis was inoculated into a $5 \mathrm{~L}$ fermenter with $5 \%$ inoculum after $24 \mathrm{~h}$, respectively; then the $\mathrm{pH}$ was adjusted to 7.0 by 2 $\mathrm{mol} / \mathrm{L} \mathrm{KOH}$ and $\mathrm{H}_{2} \mathrm{SO}_{4}$, respectively; the temperature was adjusted to $37^{\circ} \mathrm{C}$; the aeration volume was controlled to $4 \mathrm{NL} / \mathrm{min}$. During the fermentation process, the glucose was fed with $40 \%$ at a concentration of $10 \mathrm{~mL} / \mathrm{L}$ flow rate for $24 \mathrm{~h}$.

\section{Analysis Methods}

Soluble phosphorus in culture supernatant was determined by molybdate blue colorimetric method (Zhu et al., 2012). Reducing sugars were analyzed applying 3,5-Dinitrosalicylic acid (DNS) method (Deng and Tabatabai, 1994). Total sugars were assayed with sulphuric acid-phenol method (Lu et al., 2008). The microbiological analysis was carried out using plate count method (Namfon et al., 2017). Reference analysis of amino acid nitrogen (AAN) content was in accordance with the Formaldehyde Colorimetry (Zhang et al., 2018). All the experiments were conducted in triplicates.

\section{Results and Analysis}

\section{Original Colonized Microbial Diversity Investigation in CSL}

For deep understanding microbial preference in CSL, the original microbial diversity was analyzed. Results showed that the diversity of bacteria was relatively rich than fungi in CSL as show in Fig. 1. The results showed the ratio of each species as Clostridium sensu stricto (68.76\%), Bacillus (3.98\%), Brevundimonas (2.53\%), Pseudomonas (1.6\%), Lactobacillus (1.45\%), Paenibacillus (1.42\%), Lysinibacillus (1.41\%), respectively. So, the C. sensu stricto is the dominant genus of the original bacteria group in CSL. It is a strictly anaerobic bacilli, which generally produces acetic acid and butyric acids and other small organic molecules, however, it is not efficient as compared with Plant Growth-Promoting Microbes (PGPM) (Hu et al., 2016). Results shows Bacillus species take account of $3.98 \%$ in the bacterial species and it is the second dominant species in the CSL, which indicate it is compatible with the CSL environment. Meanwhile, Bacillus species are robust producing bio-fertilizers, so this study selected Bacillus spp. for CSL culture performance.

\section{Comparison of Biomass in CSL with Different Potential Strains}

Nine strains represent the robust producing biofertilizers in various application fields were tested in this part. They are B. subtilis 3301; B. subtilis A308; B. subtilis N52; B. licheniformis; S. cerevisiae; A. Niger; A. oryzae; T. harzianum; T. longi. The growth of different strains in CSL medium for $72 \mathrm{~h}$ was shown in Fig. 2. Obviously, the number of Bacillus spp. was significantly higher than that of other strains after $72 \mathrm{~h}$, which expressed obvious performance growth in CSL medium. The cells count of B. Subtilis 3301 was up to 3.1×109 CFU/mL in CSL medium. While, T. longi grew well in the CSL medium as well, which produced a large number of hyphae during liquid culture. The spore number of $T$. long $i$ was up to $7.6 \times 106 \mathrm{CFU} / \mathrm{mL}$ in CSL medium after cultivation for $72 \mathrm{~h}$ and expressed the highest living fungal count according to the cultivation result on petri dish. However, A. niger and A. oryzae showed lower growth levels (cell concentration of $3.5 \times 106 \mathrm{CFU} / \mathrm{mL}$ and $3.2 \times 106$ $\mathrm{CFU} / \mathrm{mL}$ respectively) in CSL medium culture.

And the cell number of yeast $S$. cerevisiae reached up to $5.5 \times 10^{8} \mathrm{CFU} / \mathrm{mL}$ in CSL medium after $72 \mathrm{~h}$ culture. However, the growth condition is not comparable with $S$. cerevisiae in other researches. Therefore, B. subtilis strain 3301 and $T$. longi performed better growth in CSL fermentation medium.

Comparation of Phosphorus-Dissolving Ability- A. Niger Expressed Excellent Phosphorus-Dissolving Ability

Figure 3, all strains expressed certain capacity to higher than that of other strains which dissolving organic and 
inorganic phosphorus and reached at highest $1100 \mathrm{mg} / \mathrm{L}$ inorganic phosphorus. On the other hand, the ability of dissolve organophosphorus for all other organisms were higher than that of Bacillus (the lowest is B. subtilis 3301, which shows $28 \mathrm{mg} / \mathrm{L}$ ) in this study and A. Niger and T. harzianum have a stronger dissolving capacity for organophosphorus than other strains with about $140 \mathrm{mg} / \mathrm{L}$.
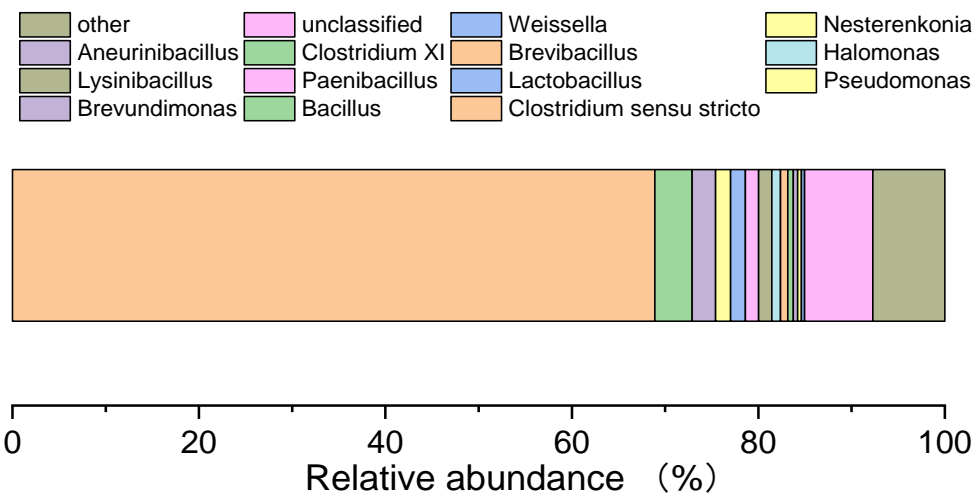

Fig. 1: Microbiome abundance of CSL sample at the level of genus

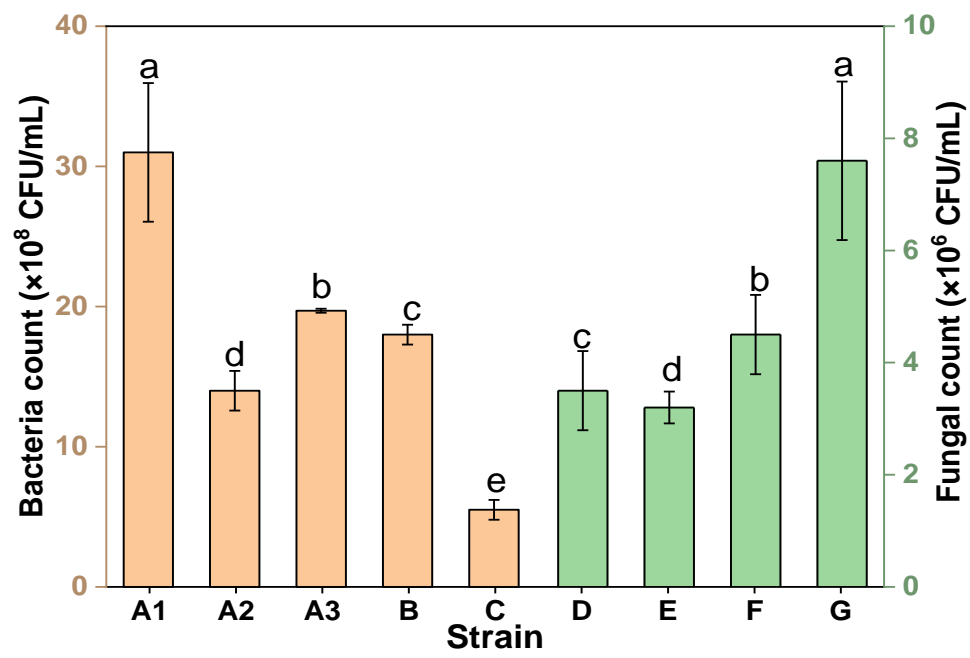

Fig. 2: Microbial count of tested stains cultivated in CSL medium for 72 h. A1: B. subtilis 3301; A2: B. subtilis A308; A3: B. subtilis N52; B: B. licheniformis; C: S. cerevisiae; D: A. Niger; E: A. oryzae; F: T. harzianum; G: T. longi. Error bars represent standard deviations $(\mathrm{n}=3)$, Lowercase letters indicate significant differences $(\mathrm{P}<0.05)$

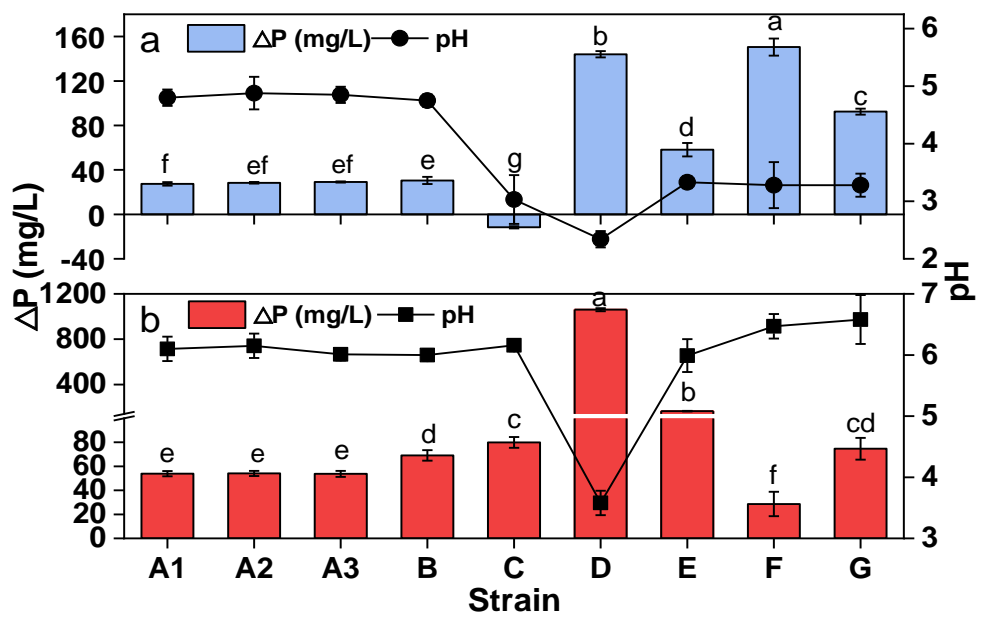




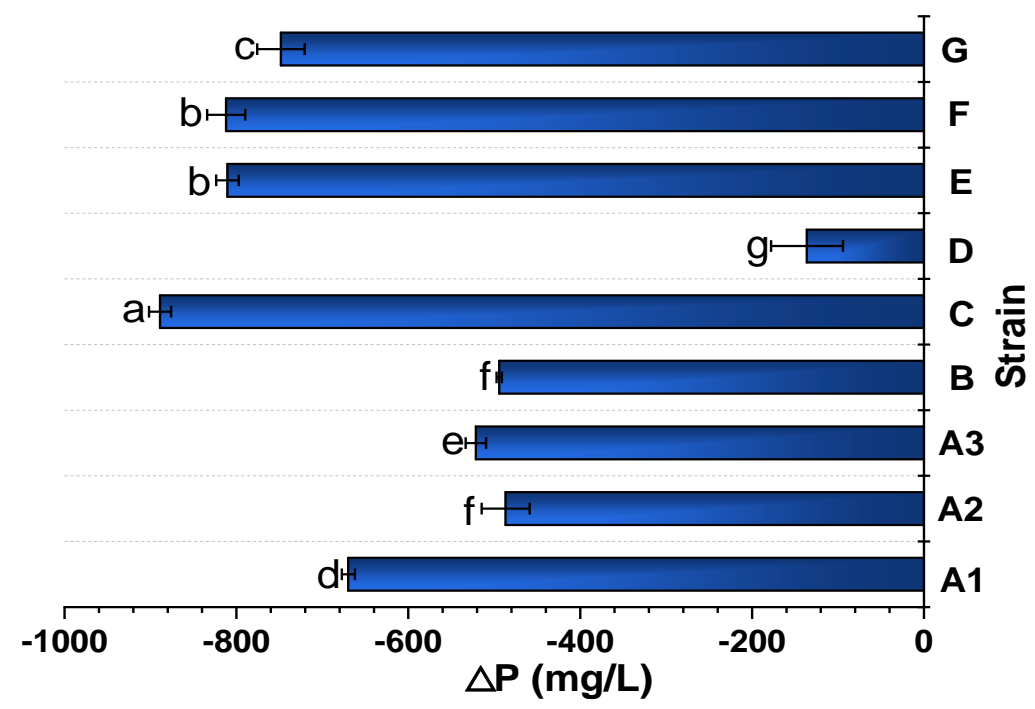

Fig. 3: The $\triangle \mathrm{P}$ and $\mathrm{pH}$ of different $\mathrm{PGPMs}$ cultivated in $\mathrm{PVK}$ medium for $72 \mathrm{~h}$. (a) $\triangle \mathrm{P}$ and $\mathrm{pH}$ in medium with organic $\mathrm{P}$; (b) $\triangle \mathrm{P}$ and $\mathrm{pH}$ in medium with inorganic $\mathrm{P}$. A1: B. subtilis 3301; A2: B. subtilis A308; A3: B. subtilis N52; B: B. licheniformis C: S. cerevisiae; D: A. Niger; E: A. oryzae; F: T. harzianum; G: T. longi. Error bars represent standard deviations $(n=3)$. Lowercase letters indicate significant differences $(P<0.05)$. The $\triangle \mathrm{P}$ of different $\mathrm{PGPMs}$ cultivated in CSL medium for $72 \mathrm{~h}$. A1: $\mathrm{B}$. subtilis 3301 ; A2: B. subtilis A308; A3: B. subtilis N52; B: B. licheniformis; C: S. cerevisiae; D: A. Niger; E: A. oryzae; F: T. harzianum; G: T. longi. Error bars represent standard deviations $(n=3)$. Lowercase letters indicate significant differences $(P<0.05)$

Meanwhile, the A. Niger expressed a lowest $\mathrm{pH}(2.3$ in organic PVK medium and 3.5 in inorganic PVK medium respectively) and all strains showed that a trend with that the low $\mathrm{pH}$ value accompanied high soluble phosphorus content. These results suggests that the low $\mathrm{pH}$ significant related to the robust conversion ability from insoluble phosphorus to soluble phosphorus. Also, our findings demonstrated that A. Niger has a stronger ability to dissolve both insoluble organic phosphorus and inorganic phosphorus than other strains, which suggested A. Niger a promising candidate for servicing a functional microorganism as bio-fertilizer.

CSL is rich in phosphorus, partially in the form of calcium and magnesium phytate. The phosphorusdissolving experiment was also tried in the CSL. The net added value $(\triangle \mathrm{P})$ of phosphorus was investigated and found soluble phosphorus of only A. Niger was significantly higher than that of other tested strains, which expressed same comparing with the results in PVK medium. The $\triangle \mathrm{P}$ was negative in the fermentation supernatant of all the strains, which indicated that, all the strains consumed the soluble phosphorus in the CSL for microbial growth. However, when added $4 \%$ glucose in CSL, the $\triangle \mathrm{P}$ value in A. Niger CSL culture changed from negative to positive, which indicates adding glucose as carbon source improved the ability of $A$. Niger to dissolve phosphorus. The results showed that soluble phosphorus could effectively promote the growth of all strains and $A$. Niger could better convert insoluble calcium magnesium phosphorus into soluble phosphorus.

\section{Amino Acid Nitrogen (AAN) Generation of PGPMs in $C S L$}

CSL is rich in soluble protein which supports excellent resource of organic nitrogen for various cells growth. AAN decomposed from protein could be directly absorbed and utilized by plant roots and soil microorganisms, a great candidate for bio-fertilizer (Zhang et al., 2016). The $\triangle \mathrm{AAN}$ value indicated the dynamic changes of amino acid nitrogen generated from protein hydrolysis in CSL by different strains. Results showed that $B$. licheniformis obtained the highest $\triangle \mathrm{AAN}$ value of $600 \mathrm{mg} / \mathrm{L}$, which means this strain has high ability for protein hydrolysis. In addition, the $\triangle \mathrm{AAN}$ in yeast was significantly lower than that in other strains, which expressed low protein hydrolysis ability.

\section{Symbiotic Fermentation Studies}

To improve the efficiency of CSL bio-fertilizers, three strains B. subtilis 3301, B. licheniformis and A. niger have been selected for mixed culture in different combinations in CSL medium for $72 \mathrm{~h}$. The cell count results were showed in Fig. 5a. It can be seen that when the three strains were mixed together $(\mathrm{A} 1+\mathrm{B}+\mathrm{D}$ as shown in Fig. 5a), the total microbial count was the highest. The bacterial count could reach $3.8 \times 10^{8} \mathrm{CFU} \cdot \mathrm{mL}^{-1}$ and the fungal count could reach $0.9 \times 10^{6} \mathrm{CFU} \cdot \mathrm{mL}^{-1}$. While when B. licheniformis and Aniger were mixed $(\mathrm{B}+\mathrm{D}$ as shown in Fig. 5a), the total cell count was the lowest, but the fungal count of $A$. niger was the highest, reached up to $5.1 \times 10^{6} \mathrm{CFU} \cdot \mathrm{mL}^{-1}$. As the $\mathrm{pH}$ could be significantly reduced by $A$. niger in the previous result. 
Our findings also indicated that the $\mathrm{pH}$ decrease affect the growth of Bacillus when Bacillus was mixed with A. Niger. Therefore, it is necessary that $\mathrm{pH}$ is controlled at an appropriate level during the symbiotic fermentation process.

The fermentation property of soluble phosphorus and amino acid nitrogen in various mixed culture in CSL medium for $72 \mathrm{~h}$ were shown in Fig. 5b. The $\triangle \mathrm{P}$ was positive when mixed with Bacillus and A. Niger (A1+D and $\mathrm{B}+\mathrm{D}$ as shown in Fig. 5b). The results indicaated that insoluble phosphorus was converted into soluble phosphorus in the mixed culture during fermentation process. The content of AAN in mixed culture of $B$. licheniformis and A. Niger (B+D as shown in Fig. 5b) was higher than other combinations, but the difference was not clear. However, during the mixed culture of B. subtilis and B. licheniformis $(\mathrm{A} 1+\mathrm{B})$ and the mixed culture of the three strains $(\mathrm{A} 1+\mathrm{B}+\mathrm{D})$, soluble phosphorus and amino acid nitrogen in the culture medium was used for self-growth and metabolism, resulting in the decrease of $\triangle \mathrm{P}$ and $\triangle \mathrm{AAN}$.

\section{The Effect of Different Neutralizer on three Selected Strains' Biomass, Phosphorus and Protein Dissolving Ability in CSL Culture}

Multiple neutralizers, $\mathrm{NaOH}, \mathrm{KOH}, \mathrm{Ca}(\mathrm{OH})_{2}$ and $\mathrm{NH}_{3} \cdot \mathrm{H}_{2} \mathrm{O}$ were applied to control the $\mathrm{pH}$ in the CSL medium and the mentioned indicators were investigated following fermentation time. The results showed that, $\mathrm{Ca}(\mathrm{OH})_{2}$ and $\mathrm{KOH}$ could increase slightly the cells count than other $\mathrm{pH}$ neutralizer. The $\triangle \mathrm{AAN}$ of each strain with $\mathrm{NH}_{3} \cdot \mathrm{H}_{2} \mathrm{O}$ as $\mathrm{pH}$ neutralizer was significantly lower than that of other $\mathrm{pH}$ neutralizers. While for soluble phosphorus generation, we found that $\mathrm{Ca}(\mathrm{OH})_{2}$ could reduce $\triangle \mathrm{P}$ in the fermentation broth. This may because the $\mathrm{Ca}^{2+}$ in $\mathrm{Ca}(\mathrm{OH})_{2}$ could chelate with phosphate radical into insoluble $\mathrm{Ca}_{3}\left(\mathrm{PO}_{4}\right)_{2}$ and reduce the content of soluble phosphorus in fermentation broth. The results showed that $\mathrm{KOH}$ had no adverse effect on fermentation if compared with other $\mathrm{pH}$, meanwhile, it could increase the $\mathrm{K}^{+}$content of fermentation broth which suitable for plant utilization. Therefore, $\mathrm{KOH}$ was defined as the appropriate $\mathrm{pH}$ neutralizer for bio-fertilizer of CSL fermentation in this study.

To evaluate the growth characteristics of three strains in CSL medium with $\mathrm{KOH}$ as a $\mathrm{pH}$ regulation, the changing of tested strains of B. subtilis 3301, B. licheniformis and A. Niger were carried out and results shown in (Fig. 7). Firstly, the three strains entered stable period after $48 \mathrm{~h}$ and living cells count seems to be stable. Secondly, the AAN of the two Bacillus species reached the highest at $48 \mathrm{~h}$ and then decreased. But A. Niger showed increasing AAN from $24 \mathrm{~h}$, because it could produce protease to decompose the protein into free amino acids after cells growth. On the contrary, phosphorus of two Bacillus species started to decrease after $24 \mathrm{~h}$ when A. Niger increase. Bacillus had low phosphorolysis capacity but cells growth consumed huge soluble phosphorus during the growth process. However, $\triangle \mathrm{P}$ first decreased and then increased in the fermentation supernatant of $A$. Niger, so the content of soluble phosphorus first decreased and then increased in the growth process. $A$. Niger has strong phosphorus hydrolysis ability and may used soluble phosphorus for its cell synthesis and at the same time, it metabolized organic acid production and phosphatase to convert insoluble phosphorus into soluble $\mathrm{P}$.

\section{Symbiotic Fermentation in 5L Scale Fermenter}

It can be seen that the logarithmic growth phases of the three strains were different during the symbiotic fermentation process in CSL. While, B. subtilis entered the logarithmic growth phase and grew rapidly to the highest cell number after $8 \mathrm{~h}$ of inoculation and the maximum cell number of B. subtilis reached $3.0 \times 109 \mathrm{CFU} \cdot \mathrm{mL}-1$ at $32 \mathrm{~h}$. Also, A. Niger entered the logarithmic phase and the maximum cell number reached $1.1 \times 106 \mathrm{CFU} \cdot \mathrm{mL}-1$ at $45 \mathrm{~h}$. Finally, B. licheniformis entered the logarithmic growth phase, with the highest cell number reaching $3.2 \times 109$ CFU.mL-1at 52 h. B. subtilis and A. Niger are aerobic microorganisms. The Dissolved Oxygen (DO) decreased rapidly from 0 to $15 \mathrm{~h}$ in the fermentation system. A. Niger quickly capture DO in the fermentation substrate for growth and metabolism. After $24 \mathrm{~h}$ inoculation with B. subtilis and $B$. licheniformis, the ventilation rate was adjusted from 2 $\mathrm{NL} / \mathrm{min}$ to $4 \mathrm{NL} / \mathrm{min}$. Competed with $A$. Niger for dissolved oxygen, $B$. subtilis quickly utilized DO in the culture medium and grew rapidly. In the late growth stage, the DO was insufficient and the number of $B$. subtilis cells slowly decreased at $32 \mathrm{~h}$. Meanwhile, A. Niger fungus start to grow till the highest number at $45 \mathrm{~h}$. B. licheniformis, as a facultative anaerobe, began to grow rapidly at $36 \mathrm{~h}$. In the late stage of growth, the nutrient substances in the medium are lacking and the numbers of $B$. licheniformis and $A$. Niger decreased. Therefore, it is necessary to extend the fixed period of $B$. subtilis by increasing the DO and feeding in the fermentor Fig. 4.

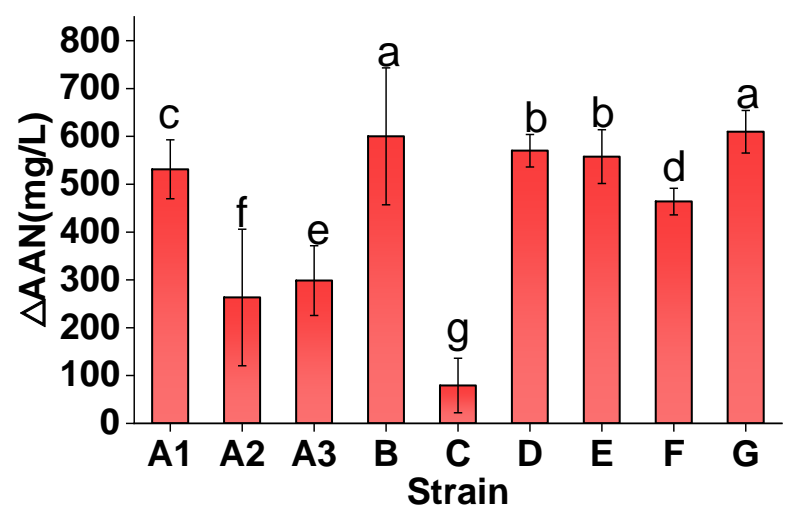

Fig. 4: The $\triangle \mathrm{AAN}$ of different PGPMs cultivated in CSL medium for $72 \mathrm{~h}$. A1: B. subtilis 3301; A2: B. subtilis A308; A3: B. subtilis N52; B: B. licheniformis; C: S. cerevisiae; D: A. niger; E: A. oryzae; F: T. harzianum; G: T. longi. Error bars represent standard deviations $(n=3)$. Lowercase letters indicate significant differences $(\mathrm{P}<0.05)$ 

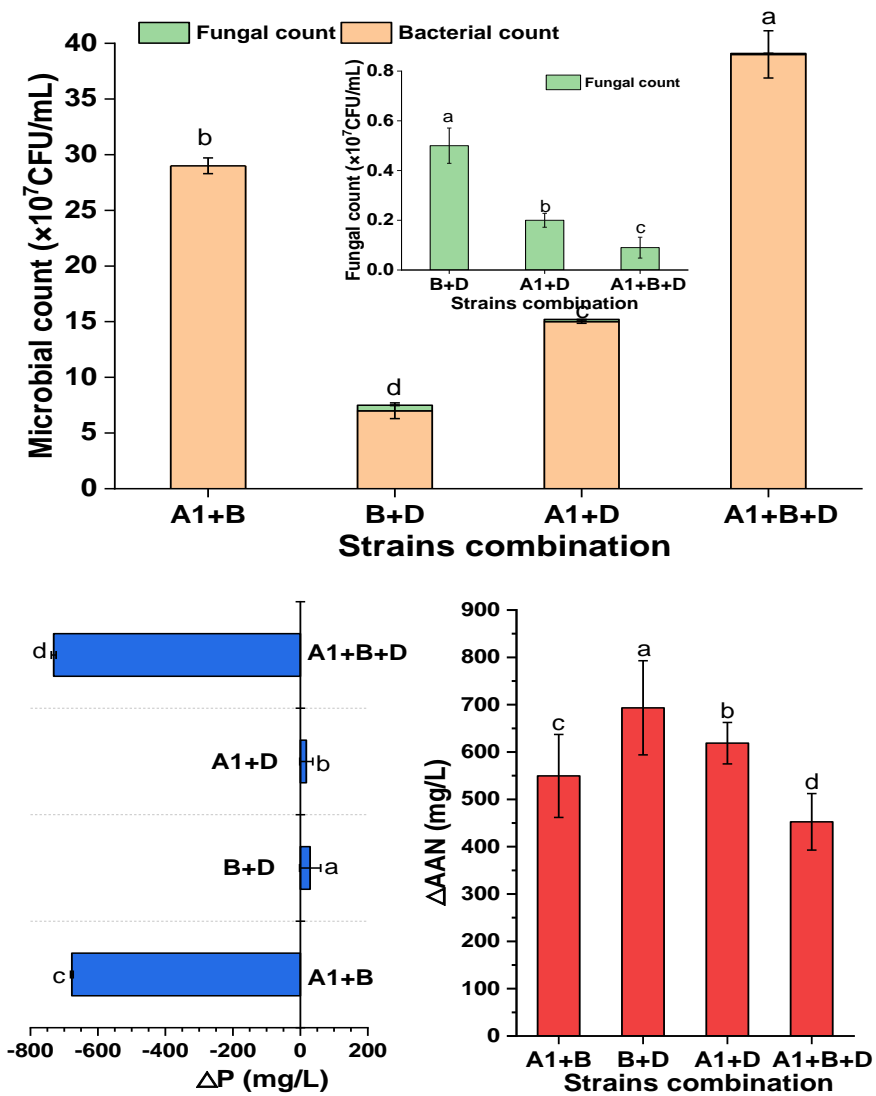

Fig. 5: Microbial count of selected strains mixed cultivated in CSL medium for 72 h. A1: B. subtilis 3301; B: B. licheniformis; D: A. Niger. Error bars represent standard deviations $(\mathrm{n}=3)$. Lowercase letters indicate significant differences $(\mathrm{P}<0.05)$ The $\triangle \mathrm{P}$ and $\triangle \mathrm{AAN}$ of selected strains mixed cultivated in CSL medium for 72 h. A1: B. subtilis 3301; B: B. licheniformis; D: A. Niger. Error bars represent standard deviations $(\mathrm{n}=3)$. Lowercase letters indicate significant differences $(\mathrm{P}<0.05)$
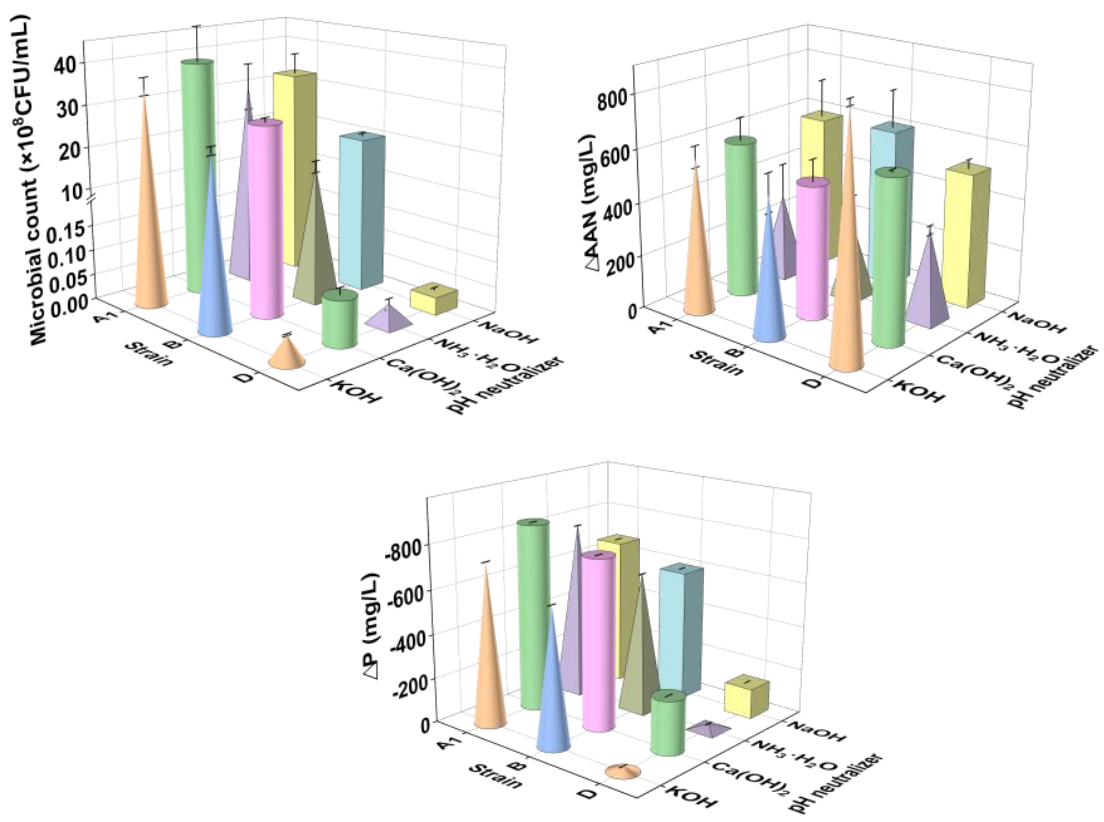

Fig. 6: Microbial count, $\triangle \mathrm{AAN}$ and $\triangle \mathrm{P}$ of selected strains cultivated in $\mathrm{CSL}$ medium with different $\mathrm{pH}$ neutralizer $(\mathrm{NaOH}, \mathrm{KOH}, \mathrm{Ca}(\mathrm{OH}) 2$, $\left.\mathrm{NH}_{3} \cdot \mathrm{H}_{2} \mathrm{O}\right)$ for 72 h. A1: B. subtilis 3301; B: B. licheniformis; D: A. Niger. Error bars represent standard deviations $(\mathrm{n}=3)$ 


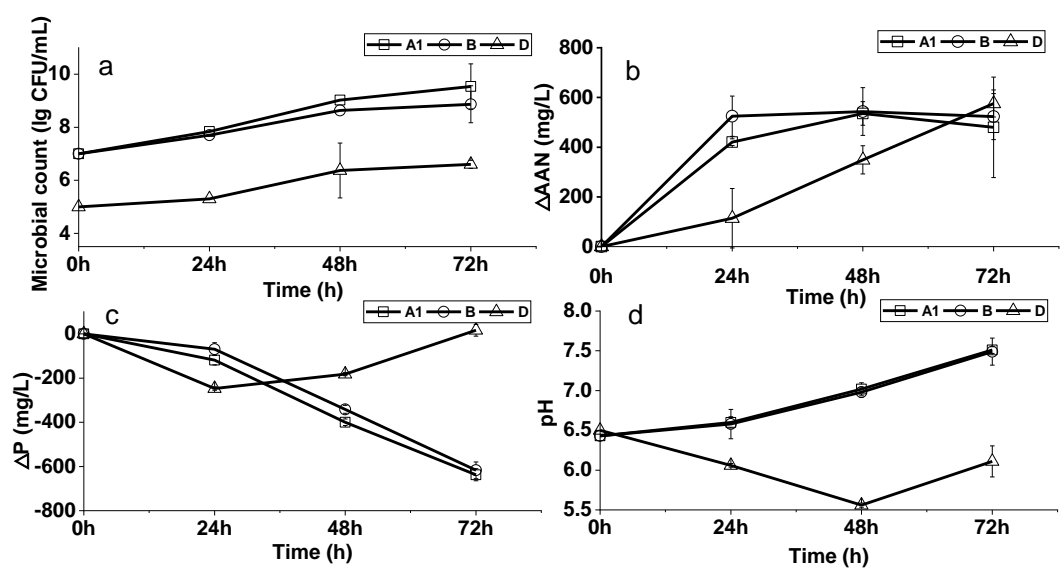

Fig. 7: Change in microbial count, $\triangle \mathrm{AAN}, \triangle \mathrm{P}$ and $\mathrm{pH}$ during cultivating in CSL medium. $\mathrm{A} 1$ : $\mathrm{B}$. subtilis 3301 ; B: $\mathrm{B}$. licheniformis; D: A. Niger. Error bars represent standard deviations $(n=3)$

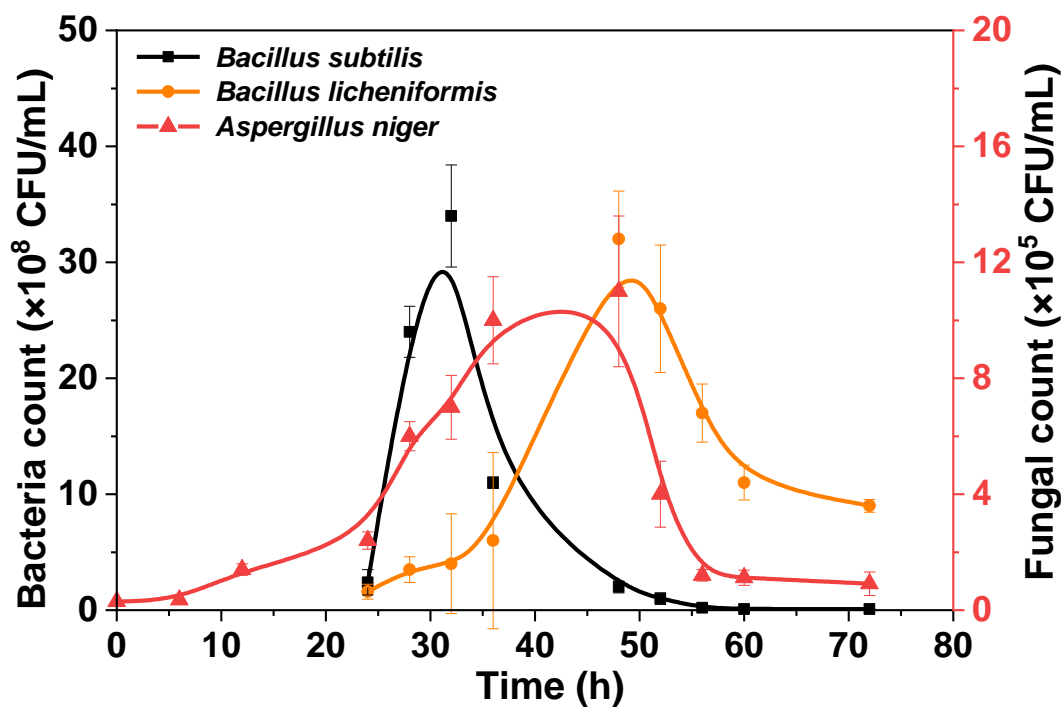

Fig. 8: Time course of microbial count during the symbiotic fermentation process in a $5 \mathrm{~L}$ fermentor. Error bars represent standard deviations $(n=3)$

Time data of the $\triangle \mathrm{P}$ and $\triangle \mathrm{AAN}$ during the symbiotic fermentation process was shown in Fig. 8. $\triangle \mathrm{AAN}$ showed the opposite trend to $\triangle \mathrm{P}$ in fermentation broth when mixed culture. $\triangle \mathrm{AAN}$ is negative at the beginning of fermentation and then $\triangle \mathrm{AAN}$ increased fastly between $24 \mathrm{~h}$ to $52 \mathrm{~h}$, which expressed a high increasing speed about $30 \mathrm{mg} \cdot \mathrm{L}^{-1} \cdot \mathrm{h}^{-1}$. Bacillus and A. Niger produces more proteases to break down the protein into amino acids during fermentation in CSL. $\triangle \mathrm{AAN}$ increased to the peak at $52 \mathrm{~h}$, then start to decrease, because the A. Niger and B. licheniformis, both reached the max biomass $\left(10.4 \times 10^{5} \mathrm{CFU} \cdot \mathrm{mL}^{-1}\right.$ and $30.0 \times 10^{8} \mathrm{CFU} \cdot \mathrm{mL}^{-1}$ respectively) at about $52 \mathrm{~h}$, which use the amino acids in CSL for growth and metabolism at the beginning of fermentation. So, the nutrient substances were deficient in CSL after $52 \mathrm{~h}$, the protein was basically decomposed and used and the microorganisms began to use amino acids for their cell growth, resulting in $\triangle \mathrm{AAN}$ reduction.

$\triangle \mathrm{P}$ is positive at the beginning of fermentation and then $\triangle \mathrm{P}$ decreased fast between $15 \mathrm{~h}$ to $35 \mathrm{~h}$, which expressed a high decreasing speed about $35 \mathrm{mg} \cdot \mathrm{L}^{-1} \cdot \mathrm{h}^{-1}$. A. Niger could convert part of insoluble phosphorus into soluble phosphorus during this period in CSL. $\triangle \mathrm{P}$ decreased to the minimum value at $52 \mathrm{~h}$, because the $A$. Niger and Bacillus reached the max biomass at about $52 \mathrm{~h}$. They converted phytic acid in CSL into free phosphate for own cell growth. Therefore, the soluble phosphorus in CSL can effectively promote the growth of functional microbe. 


\section{Discussion}

As a beneficial soil supplements, bio-fertilizers have made important contributions to ecological agriculture (Bhardwaj et al., 2014). In particularly, there is great potential to develop bio-fertilizers with agricultural waste as fermentation substrate (Du et al., 2018). For example, $\mathrm{Xu}$ et al. (2014) successfully transformed the waste water from the production of sweet potato starch into a biofertilizer for tea tree polymyxomycetes (Xu et al., 2014); Ogbo and Namfon converted cassava waste and monosodium glutamate by-product into bio-fertilizer respectively (Namfon et al., 2017; Ogbo, 2010). Many reports showed that the low concentration of CSL could promote the germination of soybean seeds and the growth of plants (Zhu et al., 2019) and it can also promote the root of lettuce and repair the soil (Chinta et al., 2014; Salam and Ishaq, 2019).

In this study, the microbial diversity of original CSL environment was analyzed by high-throughput sequencing technology, which provided a theoretical basis for understanding CSL microbial preference. Results showed that the original microbiome is in an anaerobic environment and $68.76 \%$ strains were Clostridium sensu stricto in CSL, which was the dominant group. At the same time, various Bacillus genera also take part in high abundance. Therefore, in the further study, facultative anaerobe bacteria were tried for bio-fertilizers fermentation by CSL. Finally, nine strains were collected that had been used in the bio-fertilizers industry. These strains have been shown to be effective in promoting plant growth and play an important role in agricultural production (Al-Taweil et al., 2010; García-Fraile et al., 2015; Karajeh, 2013; Kayasth et al., 2013; Ogbo, 2010; Sun et al., 2018).

An effective way to improve the sustainability of plant phosphorus nutrition is to find microorganisms with excellent phosphorus-increasing properties to produce biofertilizers. In this study, the ability of 9 strains to dissolve phosphorus were investigated. All strains have a certain ability to dissolve insoluble $\mathrm{P}$, especially A. niger species. This is basically consistent with previous studies (Kapri and Tewari, 2010; Ogbo, 2010; Paul and Rao., 1971; Rojas et al., 2001). Many researchers have studied the growth of phosphorus-dissolving bacteria in insoluble phosphorus and studied the mechanism of phosphorus-dissolving microbes (Wang et al., 2015; Whitelaw, 1999). In this study, pH was negatively correlated with the content of soluble P. This perhaps that during the fermentation process, phosphorylating microorganisms produced malic and citric acids and other organic acids that reduced the $\mathrm{pH}$ value of the fermentation broth (Zhu et al., 2012). Organic acids dissociate insoluble phosphoric acid and hydrochloric acid, chelate and exchange reactions to dissociate phosphoric acid (Illmer and Schinner, 1995). In addition, phosphatase produced by phosphorus-dissolving microorganisms also has a role in digestion and degradation of insoluble $\mathrm{P}$ (Achal et al., 2007; Raghothama, 1999).

The key fact affecting the quality of bio-fertilizer is the number of functional microorganisms. In this study, the number of viable bacillus could reach $10^{9} \mathrm{CFU} / \mathrm{mL}$ and the number of fungi can reach $10^{6} \mathrm{CFU} / \mathrm{mL}$ after $72 \mathrm{~h}$ of fermentation in CSL medium. Xu et al., 2014 optimized the conditions of fermentation sweet potato starch production wastewater and the maximum biomass of $\mathrm{P}$. polymyxa was $9.7 \times 10^{9} \mathrm{CFU} / \mathrm{mL}$ at $16 \mathrm{~h}$ (Xu et al., 2014). they indicated the bioconverted agricultural waste into compost and the fungal biomass in the compost inoculated with Aspergillus fumigatus reached a maximum of $1.7 \times 10^{6}$ CFU/g (Chang and Yang, 2009). However, CSL can achieve high fermentation density without adding other nutrients, which indicates that CSL has great advantages in the development of bio-fertilizers. Moreover, the content of soluble phosphorus of each strain in the fermentation broth increased after adding $4 \%$ glucose, indicating that the addition of glucose could increase the content of soluble phosphorus in the fermentation broth of each strain. This may be due to the increase of $\mathrm{C} / \mathrm{N}$ and organic acid content after the addition of glucose, which improves the chelation of insoluble phosphorus and other reactions and may also increase the activity of phosphatase (Relwani et al., 2008). Reported that mannitol and glucose were the best carbon sources for phosphorus dissolution in A. niger (Seshadri et al., 2004).

Based on the number of viable cell count, protein and phosphorus-dissolving capacity of 9 strains in CSL, $B$. subtilis, B. licheniformis and A. niger were selected as target strains. Three strains had a certain ability to dissolve phosphorus and notably $B$. subtilis grew rapidly in CSL with the highest number of viable bacteria and $B$. licheniformis had strong protease activity with the highest content of AAN in CSL. Kayasth et al. (2013) identified $B$. licheniformis as an ideal strain for the development of multifunctional bio-fertilizer, which can produce Indoleacetic Acid (IAA) and iron-chelating agent, dissolved phosphate and has the characteristics promoting growth plant microbe (Kayasth et al., 2013). Multiple studies have been confirmed that $B$. subtilis bacteria promotes plant growth in IAA production, biological control, soil restoration and other aspects (Idris et al., 2007; Mikutta et al., 2012; Ye et al., 2012). In addition, the phosphorus dissolution capacity of $A$. niger was significantly higher than that of other strains and was also better than that of $A$. niger which Frank C. Ogbo had reported.

CSL has a high acidity with $\mathrm{pH}$ value of about 4.3. Adjust the $\mathrm{pH}$ with conventional $\mathrm{NaOH}$ will introduce a large amount of $\mathrm{Na}+$, which will cause soil salinization. $\mathrm{Ca}(\mathrm{OH})_{2}$ is low in alkalinity which widely used as a $\mathrm{pH}$ neutralizing agent. $\mathrm{NH}_{3} \cdot \mathrm{H}_{2} \mathrm{O}$ as a $\mathrm{pH}$ neutralizing agent will make the $\mathrm{C} / \mathrm{N}$ ratio lower, which will have an adverse effect on the fermentation process and metabolites (Wang et al., 2000). 
In this study, the effects of different $\mathrm{pH}$ on the fermentation of CSL bio-fertilizer were studied. The effect of $\mathrm{KOH}$ and $\mathrm{pH}$ on the fermentation of CSL was not significantly different and the content of $\mathrm{K}^{+}$in bio-fertilizers was increased. As results demonstrated in Fig. 6, the growth of the three strains in CSL medium with $\mathrm{KOH}$ neutralizer increased. The results showed that the content of AAN and soluble phosphorus in the fermentation broth of two Bacillus spp. and A. Niger was complementary.

Symbiotic fermentation is widespread in nature and sometimes the stable co-existence of microorganisms is more effective for multiple functions than single culture (Bader et al., 2010). Marcel Gutierrez-Correa et al. (1999) studied mixed fermentation of A. Niger and Trichoderma spp. on sugarcane bagasse (Gutierrez-Correa et al., 1999). Zuroff et al. (2013) mediated cellulose into ethanol by co-culture of symbiotic Clostridium bacteria with yeast. Although studies on symbiotic fermentation have been extensively reported, different microorganisms in the coculture system may compete for the substrate and inhibit the metabolites, so co-culture has an effect on the growth of microorganisms compared to a single culture (Wu et al., 2016). In this study, B. subtilis and B. licheniformis cocultured with $A$. Niger respectively and the viable count was lower than that of single culture. The microbial count co-cultured by B. licheniformis and A. Niger was superior to that of B. subtilis and A. Niger. After co-culture with $A$. Niger, the content of soluble phosphorus in the culture solution increased, the $\mathrm{pH}$ decreased and the content of AAN increased, which also solved the adverse effect of excessive $\mathrm{pH}$ after Bacillus fermentation. The symbiotic fermentation was implemented through the fermentor and the interaction between the three strains was further tracked and evaluated in CSL. The growth of Aspergillus Niger was slow and it was inoculated at first to inhibition of inter-species competition led to the low number of microorganisms after co-culture. B. subtilis grows fast and has a high oxygen demand and it is inoculated after feeding at the later stage of fermentation and the decline of inter-microorganisms due to the lack of nutrients in the later stage. B. licheniformis is a facultative anaerobic bacterium. It should be inoculated in the middle of fermentation to increase the fermentation $\mathrm{pH}$ and decompose to produce more amino acids for later use by B. subtilis in CSL. The establishment of a symbiotic system between Bacillus and A. Niger and the increase in the number of $A$. Niger in the symbiotic system will be discussed further in future studies.

\section{Conclusion}

In this study, the original microbial community of CSL was determined. 9 selected strains were studied as bio-fertilizer PGPMs depending their capacity of dissolving phosphorus and protein, as well as biomass growth in CSL medium. Moreover, 3 strains B. subtilis, B. licheniformis and $A$. Niger were then selected for symbiotic fermentation. Based on the results, it is undeniable that this study is a systematic study on the development of biofertilizer for symbiotic fermentation of CSL and provides the importance and potential applications for the production of bio-fertilizer of CSL.

\section{Acknowledgement}

The authors are grateful to the funding support by Shandong Provincial Natural Science Foundation, China (ZR2019BC099 and ZR2020MC201); Chongqing technological innovation and application development key projects (cstc2019jscx-gksbX0113); China Postdoctoral Science Foundation, China (2019M662362 and 2019M650167).

\section{Author's Contributions}

Xiaojie Ren and Zhuangzhuang He: Participated in the whole experiment process and also contributed to the interpretation of the results and manuscript preparation.

Huihui Peng, Jing Zhang, Sihua Wang, Xiaoyu Li: Participated in part of the experimental design and manuscript preparation.

Yubin Zhao and Yuanda Song: Ameliorated the manuscript.

Xinhe Zhao and Chengye Ma: Contributed to the guidance of experimental design and ameliorated the manuscript.

\section{Ethics}

This article is original and contains unpublished material. The corresponding author confirms that all of the other authors have read and approved the manuscript and no ethical issues involved.

\section{References}

Achal, V., Savant, V. V., \& Reddy, M. S. (2007). Phosphate solubilization by a wild type strain and UV-induced mutants of Aspergillus tubingensis. Soil Biology and Biochemistry, 39(2), 695-699. doi.org/10.1016/j.soilbio.2006.09.003

Al-Taweil, H. I., Osman, M. B., Abdulhamid, A., Mohammad, N., \& Yussof, W. M. W. (2010). Comparison of different delivery system of Trichoderma and Bacillus as biofertilizer. Advances in Environmental Biology, 31-34.

Bader, J., Mast-Gerlach, E., Popović, M. K., Bajpai, R., \& Stahl, U. (2010). Relevance of microbial coculture fermentations in biotechnology. Journal of applied microbiology, 109(2), 371-387. doi.org/10.1111/j.1365-2672.2009.04659.x 
Bhardwaj, D., Ansari, M. W., Sahoo, R. K., \& Tuteja, N. (2014). Biofertilizers function as key player in sustainable agriculture by improving soil fertility, plant tolerance and crop productivity. Microbial cell factories, 13(1), 1-10. doi.org/10.1186/1475-2859-13-66

Chang, C. H., \& Yang, S. S. (2009). Thermo-tolerant phosphate-solubilizing microbes for multi-functional biofertilizer preparation. Bioresource Technology, 100(4), 1648-1658. doi.org/10.1016/j.biortech.2008.09.009

Chinta, Y. D., Kano, K., Widiastuti, A., Fukahori, M., Kawasaki, S., Eguchi, Y., ... \& Sato, T. (2014). Effect of corn steep liquor on lettuce root rot (Fusarium oxysporum f. sp. lactucae) in hydroponic cultures. Journal of the Science of Food and Agriculture, 94(11), 2317-2323. doi.org/10.1002/jsfa.6561

Deng, S. P., \& Tabatabai, M. A. (1994). Colorimetric determination of reducing sugars in soils. Soil Biology and Biochemistry, 26(4), 473-477. doi.org/10.1016/0038-0717(94)90179-1

Du, C., Abdullah, J. J., Greetham, D., Fu, D., Yu, M., Ren, L., ... \& Lu, D. (2018). Valorization of food waste into biofertiliser and its field application. Journal of Cleaner Production, 187, 273-284. doi.org/10.1016/j.jclepro.2018.03.211

Filipović, S. S., Ristić, M. D., \& Sakač, M. B. (2001). Technology of corn steep application in animal mashes and their quality. Roumanian Biotechnology Letters, 7705-710. https://e-repository.org/rbl/vol.7/iss.3/2.pdf

García-Fraile, P., Menéndez, E., \& Rivas, R. (2015). Role of bacterial biofertilizers in agriculture and forestry. AIMS Bioengineering, 2(3), 183-205.

doi.org/10.3934/bioeng.2015.3.183

Gutierrez-Correa, M., Portal, L., Moreno, P., \& Tengerdy, R. P. (1999). Mixed culture solid substrate fermentation of Trichoderma reesei with Aspergillus niger on sugar cane bagasse. Bioresource Technology, 68(2), 173-178. doi.org/10.1016/S0960-8524(98)00139-4

$\mathrm{Hu}, \mathrm{X} ., \mathrm{Du}, \mathrm{H} ., \mathrm{Ren}, \mathrm{C} .$, \& Xu, Y. (2016). Illuminating anaerobic microbial community and cooccurrence patterns across a quality gradient in Chinese liquor fermentation pit muds. Applied and environmental microbiology, 82(8), 2506-2515. doi.org/10.1128/AEM.03409-15

Idris, E. E., Iglesias, D. J., Talon, M., \& Borriss, R. (2007). Tryptophan-dependent production of indole3 -acetic acid (IAA) affects level of plant growth promotion by Bacillus amyloliquefaciens FZB42. Molecular plant-microbe interactions, 20(6), 619-626. doi.org/10.1094/MPMI-20-6-0619

Illmer, P., \& Schinner, F. (1995). Solubilization of inorganic calcium phosphates-solubilization mechanisms. Soil Biology and Biochemistry, 27(3), 257-263. doi.org/10.1016/0038-0717(94)00190-C
Kapri, A., \& Tewari, L. (2010). Phosphate solubilization potential and phosphatase activity of rhizospheric Trichoderma spp. Brazilian Journal of Microbiology, 41, 787-795. doi.org/10.1590/S1517-83822010005000001

Karajeh, M. R. (2013). Efficacy of Saccharomyces cerevisiae on controlling the root-knot nematode (Meloidogyne javanica) infection and promoting cucumber growth and yield under laboratory and field conditions. Archives of Phytopathology and Plant Protection, 46(20), 2492-2500. doi.org/10.1080/03235408.2013.799819

Kayasth, M., Kumar, V., \& Gera, R. (2013). Exploring the potential of PGPR strain Bacillus licheniformis to be developed as multifunctional biofertilizer. Central European Journal of Biology, 2(1), 12-17.

Liggett, R. W., \& Koffler, H. (1948). Corn steep liquor in microbiology. Bacteriological reviews, 12(4), 297-311. doi.org/10.1128/br.12.4.297-311.1948

Lu, X., Chen, Z., Gu, Z., \& Han, Y. (2008). Isolation of $\gamma$-aminobutyric acid-producing bacteria and optimization of fermentative medium. Biochemical Engineering Journal, 41(1), 48-52. doi.org/10.1016/j.bej.2008.03.005

Mikutta, R., Baumgärtner, A., Schippers, A., Haumaier, L., \& Guggenberger, G. (2012). Extracellular polymeric substances from Bacillus subtilis associated with minerals modify the extent and rate of heavy metal sorption. Environmental science \& technology, 46(7), 3866-3873. doi.org/10.1021/es204471x

Namfon, P., Ratchanok, S., \& Chalida, D. (2017, March). Optimization of the liquid biofertilizer production in batch fermentation with by-product from MSG. In AIP Conference Proceedings (Vol. 1823, No. 1, p. 020074). AIP Publishing LLC. doi.org/10.1063/1.4978147

Obayori, O. S., Salam, L. B., Anifowoshe, W. T., Odunewu, Z. M., Amosu, O. E., \& Ofulue, B. E. (2015). Enhanced degradation of petroleum hydrocarbons in corn-steep-liquor-treated soil microcosm. Soil and Sediment Contamination: An International Journal, 24(7), 731-743. doi.org/10.1080/15320383.2015.1020409

Ogbo, F. C. (2010). Conversion of cassava wastes for biofertilizer production using phosphate solubilizing fungi. Bioresource technology, 101(11), 4120-4124. doi.org/10.1016/j.biortech.2009.12.057

Paul, N. B., \& Rao, W. S. (1971). Phosphate-dissolving bacteria in the rhizosphere of some cultivated legumes. Plant and soil, 35(1), 127-132. doi.org/10.1007/BF01372637

Raghothama, K. G. (1999). Phosphate acquisition. Annual review of plant biology, 50(1), 665-693. doi.org/10.1146/annurev.arplant.50.1.665 
Relwani, L., Krishna, P., \& Reddy, M. S. (2008). Effect of carbon and nitrogen sources on phosphate solubilization by a wild-type strain and UV-induced mutants of Aspergillus tubingensis. Current microbiology, 57(5), 401-406. doi.org/10.1007/s00284-008-9212-y

Rojas, A., Holguin, G., Glick, B. R., \& Bashan, Y. (2001). Synergism between Phyllobacterium sp.(N2-fixer) and Bacillus licheniformis (P-solubilizer), both from a semiarid mangrove rhizosphere. FEMS Microbiology Ecology, 35(2), 181-187. doi.org/10.1111/j.1574-6941.2001.tb00802.x

Salam, L. B., \& Ishaq, A. (2019). Biostimulation potentials of corn steep liquor in enhanced hydrocarbon degradation in chronically polluted soil. 3 Biotech, 9(2), 46. doi.org/10.1007/s13205-019-1580-4

Seshadri, S., Ignacimuthu, S., \& Lakshminarasimhan, C. (2004). Effect of nitrogen and carbon sources on the inorganic phosphate solubilization by different Aspergillus niger strains. Chemical Engineering Communications, 191(8), 1043-1052. doi.org/10.1080/00986440490276308

Sun, B. T., Akutse, K. S., Xia, X. F., Chen, J. H., Ai, X., Tang, Y., ... \& You, M. S. (2018). Endophytic effects of Aspergillus oryzae on radish (Raphanus sativus) and its herbivore, Plutella xylostella. Planta, 248(3), 705-714. doi.org/10.1007/s00425-018-2928-4

Wang, H. Y., Shen, L. I. U., Zhai, L. M., Zhang, J. Z., Ren, T. Z., Fan, B. Q., \& LIU, H. B. (2015). Preparation and utilization of phosphate biofertilizers using agricultural waste. Journal of Integrative Agriculture, 14(1), 158-167. doi.org/10.1016/S2095-3119(14)60760-7

Wang, J. F., Liang, S. Z., Zhen-Qiang, W. U., Tan, Z. L., $\&$ Chen, F. (2000). Effect of carbon source and high $\mathrm{C} / \mathrm{N}$ ratio in the cellulosic hydrolysate- based media on the crude lipid contents and unsaturated fatty acid compositions of yeasts. 2000, 28(10), 28-31.

Whitelaw, M. A. (1999). Growth promotion of plants inoculated with phosphate-solubilizing fungi. Advances in agronomy, 69, 99-151. doi.org/10.1016/S0065-2113(08)60948-7

Wu, P., Wang, G., Wang, G., Børresen, B. T., Liu, H., \& Zhang, J. (2016). Butanol production under microaerobic conditions with a symbiotic system of Clostridium acetobutylicum and Bacillus cereus. Microbial cell factories, 15(1), 1-11. doi.org/10.1186/s12934-016-0412-Z

Xu, S., Bai, Z., Jin, B., Xiao, R., \& Zhuang, G. (2014). Bioconversion of wastewater from sweet potato starch production to Paenibacillus polymyxa biofertilizer for tea plants. Scientific reports, 4(1), 1-7. doi.org/10.1038/srep04131
Ye, Y. F., LI, Q. Q., Gang, F. U., Yuan, G. Q., MIAO, J. H., \& Wei, L. I. N. (2012). Identification of antifungal substance (Iturin A2) produced by Bacillus subtilis B47 and its effect on southern corn leaf blight. Journal of Integrative Agriculture, 11(1), 90-99. doi.org/10.1016/S1671-2927(12)60786-X

Zhang, F., Meng, X., Feng, C., Ran, W., Yu, G., Zhang, Y., \& Shen, Q. (2016). Hydrolytic amino acids employed as a novel organic nitrogen source for the preparation of PGPF-containing bio-organic fertilizer for plant growth promotion and characterization of substance transformation during BOF production. PloS one, 11(3), e0149447. doi.org/10.1371/journal.pone.0149447

Zhang, J., \& Jia, B. (2018). Enhanced butanol production using Clostridium beijerinckii SE-2 from the waste of corn processing. Biomass and Bioenergy, 115, 260-266. doi.org/10.1016/j.biombioe.2018.05.012

Zhang, Y., Yang, G., \& Li, D. (2018). Determination of Amino Acid Nitrogen in Soy Sauce by Colorimetry. China Condiment, 43(06), 146-149. doi.org/10.1086/694697

Zhao, X., He, Z., Zhao, Y. (2020). Kinetic simulation of amino acid metabolism of butanol produced from the fermentation of corn steep liquor[J]. Transactions of the Chinese Society of Agricultural Engineering (Transactions of the CSAE), 2020, 36(18): 263-274.

Zhu, H. J., Sun, L. F., Zhang, Y. F., Zhang, X. L., \& Qiao, J. J. (2012). Conversion of spent mushroom substrate to biofertilizer using a stress-tolerant phosphate-solubilizing Pichia farinose FL7. Bioresource technology, 111, 410-416. doi.org/10.1016/j.biortech.2012.02.042

Zhu, M. M., Liu, E. Q., Bao, Y., Duan, S. L., She, J., Liu, H., ... \& Guo, X. T. (2019). Low concentration of corn steep liquor promotes seed germination, plant growth, biomass production and flowering in soybean. Plant Growth Regulation, 87(1), 29-37. doi.org/10.1007/s10725-018-0449-6

Zuroff, T. R., Xiques, S. B., \& Curtis, W. R. (2013). Consortia-mediated bioprocessing of cellulose to ethanol with a symbiotic Clostridium phytofermentans/yeast co-culture. Biotechnology for biofuels, 6(1), 1-12. doi.org/10.1186/1754-6834-6-59 